\title{
The rheological behavior of crude oil in the presence of palm oil additives
}

\author{
Thevaruban Ragunathan ${ }^{1}$ (I) $\cdot$ Jazeel Zaqwan ${ }^{1} \cdot$ Colin D. Wood $^{2} \cdot$ Hazlina Husin ${ }^{1}$
}

Received: 15 March 2021 / Accepted: 19 May 2021 / Published online: 5 June 2021

(c) The Author(s) 2021

\begin{abstract}
Wax precipitation has become a serious problem for the petroleum industry. The problem occurs when there is equilibrium disturbance on the pressure and temperature as well as crude oil composition. Wax deposits will eventually result in restriction of the fluid flow inside the pipeline, and severe deposition will cause blockage. The chemical additives currently being implemented in the industry have various limitations including the high cost and the irreversible impact it has on the environment. Therefore, the use of cheaper organic wax inhibitor obtained from crude palm oil (CPO) and crude palm kernel oil (CPKO) on the rheology and deposition of wax was investigated by using Chenor waxy crude oil from the Penyu basin, Pahang, Malaysia. To compare the efficiency of palm oil additives in inhibiting wax deposition, currently utilized chemical additives such as triethanolamine (TEA) and ethylene vinyl acetate (EVA) were also examined. The pour point of the crude oil was determined using SETA cloud \& cryostat, while the rheological behavior of the crude was determined using a rotational Fann viscometer. The results obtained from this study reveal that CPO and CPKO could be used to improve the flow of crude oil, especially when $1 \mathrm{wt}$ \% CPO or when $0.5 \mathrm{wt}$ \% CPKO is used. It was also noted that the palm-based additives were much more effective at reducing the viscosity of the Chenor crude oil than the commercial wax inhibitor tested (TEA and EVA).
\end{abstract}

Keywords Paraffin wax $\cdot$ Chemical wax inhibitors $\cdot$ Rheological properties $\cdot$ Palm oil inhibitors $\cdot$ Fann viscometer

$\begin{array}{ll}\text { Abbreviations } \\ \text { API } & \text { American petroleum index } \\ \text { CPKO } & \text { Crude palm kernel oil } \\ \text { CPO } & \text { Crude palm oil } \\ \text { CSO } & \text { Castor seed oil } \\ \text { EVA } & \text { Ethylene vinyl acetate } \\ \text { JSO } & \text { Jatropha seed oil } \\ \text { PIE } & \text { Paraffin inhibition efficiency } \\ \text { RSO } & \text { Rubber seed oil } \\ \text { TEA } & \text { Triethanolamine } \\ \text { WAT } & \text { Wax appearance temperature } \\ \text { RPM } & \text { Revolutions per minute }\end{array}$

Thevaruban Ragunathan thevruban@gmail.com

1 Universiti Teknologi PETRONAS, Bandar Seri Iskandar, 31750 Seri Iskandar, Perak Darul Ridzuan, Malaysia

2 CSIRO Energy Business Unit, 26 Dick Perry Avenue, Kensington Western Australia 6102, Australia

\section{Introduction}

Currently, the petroleum industry is trying to find a cheaper solution to flow assurance problems that occur during the transportation of crude oil to justify the economical production of crude oil (Sadeq et al. 2020; Ottha and Al-Jawad 2006; Brown 2002). Among the flow assurance issue, the precipitation of wax inside the tubing and the pipeline during the production of crude oil is a major challenge. In tropical waters such as Malaysia, the average seabed temperature ranges from $4{ }^{\circ} \mathrm{C}$ to $7{ }^{\circ} \mathrm{C}$ which often leads to wax precipitation as the crude oil drops below the wax appearance temperature and later the deposition of wax onto the pipe wall due to molecular diffusion (Sulaimon and Yusoff 2014). The deposition of wax onto the pipe wall causes the decrease in the tubing inner diameter, therefore requiring higher pressure to transport the crude oil through the pipeline. Due to this pressure drop during the production and transportation process, a decrease in the oil flowrate will be observed (Anisuzzaman et al. 2017).

Crude oil consists mainly of asphaltenes, aromatic, resins and saturates, while the main component of saturates is paraffin (Al-Jawad and Hassan 2012; Garcia 2000; McCain

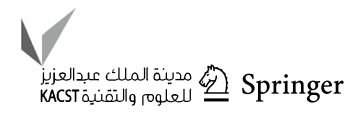


2017). High molecular weight of the n-alkenes (n-paraffins) usually precipitates and deposits out from the crude oil onto the pipe wall. Hence, wax precipitation is an undesirable condition in the petroleum industry as it is the initial stage that leads to the plugging of pipelines and other process equipment (Azzam et al. 2018). Furthermore, many oil wells and facilities have been abandoned due to the intense wax deposition. In some oil fields, millions of dollars have been spent to tackle the wax deposition problem (Kelechukwu et al. 2013). Hence, to deal with the deposition of wax, most production companies implement the use of chemical inhibitors such as ethylene vinyl acetate (EVA) and triethanolamine (TEA) (Popoola et al. 2015; Zhang et al. 2008). However, the chemical inhibitors currently used in the industry significantly increase the operating cost of the pipeline and possess an environmental threat if there is a spill as it is not biodegradable. This has prompted the need to find a cheaper and safer alternative to be used as a wax chemical inhibitor. Few researches have been conducted on using plant-based additives as potential chemical inhibitors(Akinyemi et al. 2016; Akinyemi et al. 2018; Hafiz and Khidr 2007; Patel et al. 2017; Soni et al. 2010). From the research conducted by Akinyemi et al. whereby the authors used plant seed oils such as jatropha (JSO), rubber (RSO) and castor (CSO) as potential chemical additives in Nigerian waxy crude oil, portrayed that the plant seed oils were able to reduce the deposition of wax as efficient as commercial inhibitors (EVA). The authors then further concluded in their research that the high composition of oleic acid in the plant seed oils is the main factor to the high inhibition efficiency (Akinyemi et al. 2016; Akinyemi et al. 2018). The authors then concluded that at high concentrations, the synthesized flow improvers are excellent pour-point depressants which reduce the apparent viscosity, plastic viscosity as well as the yield value of the Langhnaj crude oil (Hafiz and Khidr 2007; Patel et al. 2017; Soni et al. 2010). Also, viscosity is an essential part in the investigation of wax inhibition effectiveness as viscosity portrays a significant aspect in the ability of the crude oil to flow. Therefore, the apparent viscosity, plastic viscosity and the yield value of the crude oil in the presence and absence of additives were investigated. Apparent viscosity is defined as the ratio between instantaneous shear stress and shear rate, while plastic viscosity is the resistance of the fluid to flow (Ridzuan et al. 2014; Patel et al. 2017). Meanwhile, yield value is the resistance or stress required of a fluid to start flowing (Patel et al. 2017).

Hence, this paper investigates the effect of palm oil additives which consists of high concentration of oleic acid and its isomers on the rheological behavior of waxy crude oil at various concentrations and temperatures. Table 1 portrays the composition of the fatty acids of the palm oil additives used in this study which are crude palm oil (CPO) and crude palm kernel oil (CPKO). This paper also compares the
Table 1 Composition of fatty acids in CPO and CPKO (Malaysian Palm Oil Council 2012)

\begin{tabular}{|c|c|c|c|}
\hline Fatty Acid & Lipid number & CPO, $\%$ & СРКО, $\%$ \\
\hline Capric acid & C10:0 & - & 3.7 \\
\hline Lauric acid & $\mathrm{C} 12: 0$ & 0.5 & 15.3 \\
\hline Myristic acid & $\mathrm{C} 14: 0$ & 1.5 & 15.6 \\
\hline Palmitic acid & C16:0 & 34.5 & 7.8 \\
\hline Palmitoleic acid & C16:1 & 0.4 & - \\
\hline Stearic acid & C18:0 & 5.4 & 2 \\
\hline Oleic acid & C18:1 & 44.1 & 48.2 \\
\hline Linoleic acid & C18:2 & 12.5 & 2.7 \\
\hline$\alpha$-Linolenic acid & $\mathrm{C} 18: 3$ & 0.6 & - \\
\hline Arachidic acid & C20:0 & 0.5 & - \\
\hline Caproic acid & C6:0 & - & 0.3 \\
\hline Caprylic acid & $\mathrm{C} 8: 0$ & - & 4.4 \\
\hline 9,10-Dihydroxystearic & - & - & - \\
\hline
\end{tabular}

Table 2 Physical and chemical properties of crude oil sample

\begin{tabular}{ll}
\hline Chemical properties & Crude oil \\
\hline Density & $0.8033 \mathrm{~g} / \mathrm{cm}^{3}$ \\
API gravity & $44.65 \mathrm{API}$ \\
Wax appearance temperature/cloud point & $35^{\circ} \mathrm{C}$ \\
Pour point & $10^{\circ} \mathrm{C}$ \\
Wax content $(\mathrm{wt} \%)$ & 8.26 \\
\hline
\end{tabular}

efficiency of the palm oil additives to the commercially used wax inhibitor which are triethanolamine (TEA) and ethylene vinyl acetate (EVA), where this study finds that the palm oil additives are more effective at reducing the viscosity of the Chenor crude oil than the commercial wax inhibitor tested

\section{Methodology}

\section{Materials}

The palm oil (CPO) and palm kernel oil (CPKO) were obtained from United Plantation and Unitata, respectively. The crude oil was used from the Chenor oil field in the Penyu basin, Pahang, Malaysia, while the triethanolamine (TEA) and ethylene vinyl acetate (EVA) were purchased from Sigma-Aldrich.

\section{Characterization of the crude oil sample}

The physical and the chemical properties of the crude oil are as shown in Table 2 . The density, specific gravity and the API gravity are obtained using a densitometer with a standard deviation of $0.001 \mathrm{~g} / \mathrm{cm}^{3}$. The wax appearance 
temperature (WAT) and the pour point of the crude oil were obtained using the SETA pour point and cloud point apparatus with a standard deviation of $0.82{ }^{\circ} \mathrm{C}$. The wax content of the crude oil was obtained using the wax content analyser with a standard deviation of $0.55 \mathrm{wt} . \%$.

\section{Rheological properties}

The rheological properties of the crude oil in the presence and absence of additives were investigated using the Fann viscometer model 35SA. Firstly, the crude was heated up to $70{ }^{\circ} \mathrm{C}$ to eliminate previous wax history. The measurement was done at various temperatures and speed starting from $600 \mathrm{rpm}$ to $3 \mathrm{rpm}$. The value of viscosity was obtained by reading the dial when it is steady and stopped moving. Besides, the apparent and plastic viscosity, as well as yield value, was obtained using the standard equation as shown in Eqs. 1, 2 and 3, respectively.

Apparent viscosity $=\frac{\text { Dial reading at600rpm }}{2} \mathrm{cPs}$

Plastic viscosity $=($ Dial reading at $600 \mathrm{rpm}$

$$
\text { - Dial reading at } 300 \mathrm{rpm}) \mathrm{cPs}
$$

Yield value $=($ Dial reading at $300 \mathrm{rpm}$

$$
\text { - Plastic viscosity) } \mathrm{lb} / 100 \mathrm{ft}^{2}
$$

The experiment was then repeated with the addition of CPO, CPKO and TEA at concentration of $0.1,0.5,1,5$ and $10 \mathrm{wt} \%$, respectively. The setup of the experiment is shown in Fig. 1.

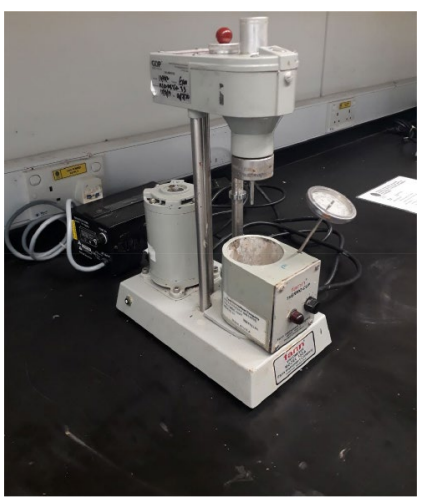

Fig. 1 Fann viscometer model 35SA

\section{Results and discussion}

\section{Apparent viscosity}

Apparent viscosity is defined as the ratio between instantaneous shear stress and shear rate (Ridzuan et al. 2014). It was observed that all the inhibitors tested were able to reduce the apparent viscosity significantly up to the optimum concentration as compared to virgin crude oil. Figures 2, 3, 4, 5 and 6 illustrate the apparent viscosity results.

From Fig. 2, it can be seen that the presence of CPO in all the concentration tested was able to reduce the apparent viscosity of the crude oil as all the viscosity curves in the presence of CPO inhibitor are below the viscosity curve of virgin crude oil. Furthermore, it can be seen as the concentration of the $\mathrm{CPO}$ additive increases from $0.1 \mathrm{wt} . \%$ to $1 \mathrm{wt} . \%$, the apparent viscosity decreases with $1 \mathrm{wt} . \%$ concentration being the lowest apparent viscosity. However, as the concentration of the $\mathrm{CPO}$ inhibitor further increases to $5 \mathrm{wt} . \%$ and $10 \mathrm{wt} . \%$, the apparent viscosity increases with $10 \mathrm{wt} . \%$ CPO portraying the highest apparent viscosity

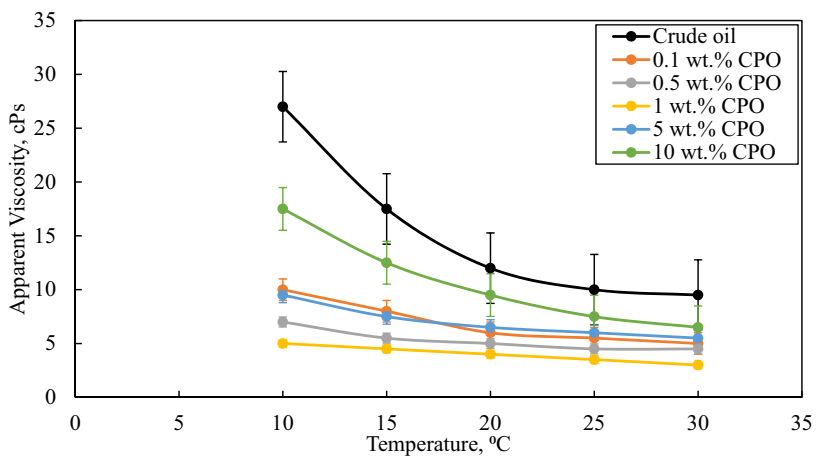

Fig. 2 Apparent viscosity of crude oil in the presence of various concentrations of $\mathrm{CPO}$

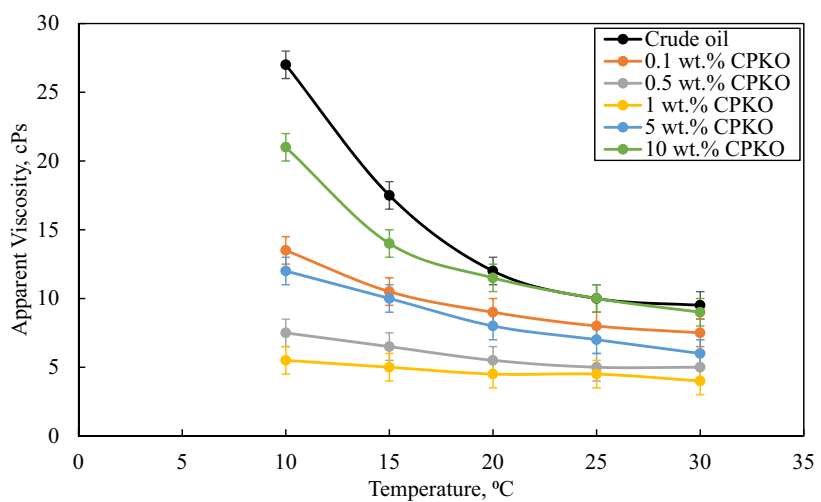

Fig. 3 Apparent viscosity of crude oil in the presence of various concentrations of CPKO 


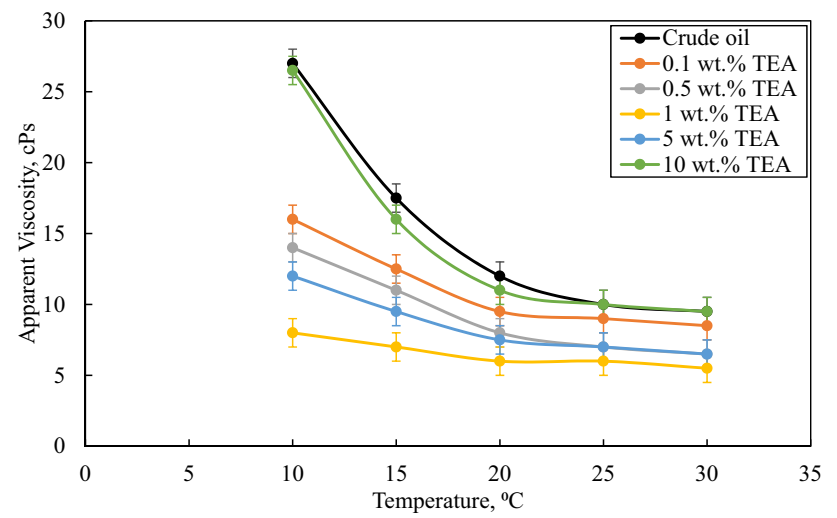

Fig. 4 Apparent viscosity of crude oil in the presence of various concentrations of TEA

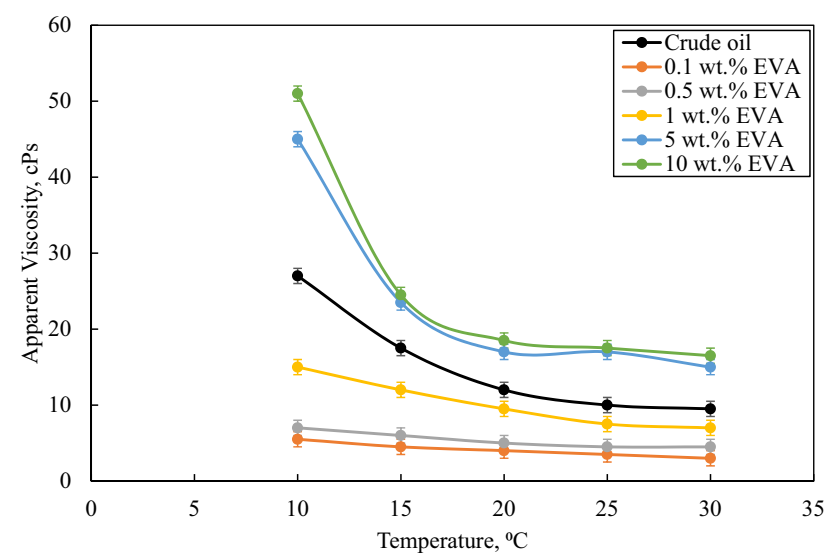

Fig. 5 Apparent viscosity of crude oil in the presence of various concentrations of EVA

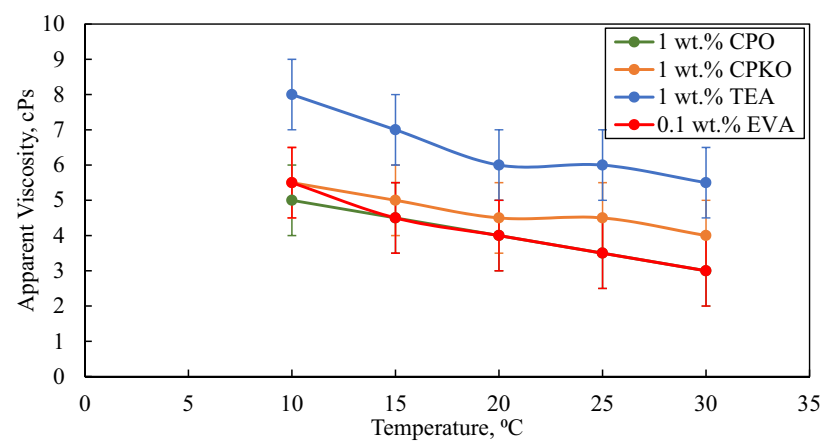

Fig. 6 Apparent viscosity of the most efficient inhibitor concentrations

among the CPO concentration tested. Therefore, the optimum concentration of CPO is $1 \mathrm{wt} . \%$ for Chenor crude oil.

From Fig. 3, it can be concluded that the presence of $\mathrm{CPKO}$ in the various concentrations tested is able to reduce the apparent viscosity of the crude oil as all the viscosity curves in the presence of CPKO inhibitor are below the viscosity curve of virgin crude oil. Moreover, it can be seen as the concentration of the CPKO additive increases from $0.1 \mathrm{wt} . \%$ to $1 \mathrm{wt} . \%$, the apparent viscosity decreases with $1 \mathrm{wt} . \%$ concentration being the lowest apparent viscosity (critical concentration). However, as the concentration of the CPKO inhibitor further increases to $5 \mathrm{wt} . \%$ and $10 \mathrm{wt} . \%$, the apparent viscosity increases with $10 \mathrm{wt}$ \% CPKO portraying the highest apparent viscosity which is almost similar to the apparent viscosity of the virgin crude oil at high temperature. When comparing the apparent viscosity of CPO and $\mathrm{CPKO}, \mathrm{CPKO}$ portrayed the highest efficiency in reducing the apparent viscosity of the Chenor crude oil.

Based on Fig. 4, it can be determined that the presence of various concentrations of TEA tested is able to reduce the apparent viscosity of the crude oil as all the viscosity curves in the presence of TEA inhibitor are below the viscosity curve of virgin crude oil. Moreover, it can be seen as the concentration of the TEA additive increases from $0.1 \mathrm{wt} . \%$ to $1 \mathrm{wt} . \%$, the apparent viscosity decreases with $1 \mathrm{wt} . \%$ concentration being the most efficient in reducing the apparent viscosity of the crude oil (critical concentration). However, as the concentration of the TEA inhibitor further increases to $5 \mathrm{wt} . \%$ and $10 \mathrm{wt} . \%$, the apparent viscosity increases with $10 \mathrm{wt} . \%$ TEA portraying the highest apparent viscosity which is almost similar to the apparent viscosity of the virgin crude oil. When comparing the apparent viscosity of TEA with CPO and CPKO, CPO still portrays the highest efficiency in reducing the apparent viscosity of the Chenor crude oil.

Based on Fig. 5, it can be concluded that the presence of EVA at low concentration is able to reduce the apparent viscosity of the crude oil as the viscosity curves of $0.1 \mathrm{wt} . \%$, $0.5 \mathrm{wt} . \%$ and $1 \mathrm{wt} . \%$ EVA are below the viscosity curve of virgin crude oil. Besides, it can be seen as the concentration of the EVA additive increases from $0.1 \mathrm{wt} . \%$ to $0.5 \mathrm{wt} . \%$, the apparent viscosity decreases with $0.5 \mathrm{wt} . \%$ concentration being the most efficient in reducing the apparent viscosity of the crude oil (critical concentration). Meanwhile, as the concentration of the EVA inhibitor further increases to $1 \mathrm{wt} . \%$, $5 \mathrm{wt} . \%$ and $10 \mathrm{wt} . \%$, the apparent viscosity increases with $5 \mathrm{wt} . \%$ and $10 \mathrm{wt} . \%$ EVA portraying the highest apparent viscosity which is significantly higher than the apparent viscosity of the virgin crude oil. When comparing the apparent viscosity of EVA with the other inhibitors tested, $0.1 \mathrm{wt} . \%$ EVA and $1 \mathrm{wt}$.\% CPO portray the lowest apparent viscosity for the Chenor crude oil. To get a better understanding on the most efficient inhibitor used for Chenor crude oil, the concentration which has the lowest apparent viscosity of each inhibitor is plotted as illustrated in Fig. 6. Moreover, the apparent viscosity of the best performing inhibitor formulation compared to the apparent viscosity of the virgin crude oil is as shown in Fig. 7. 


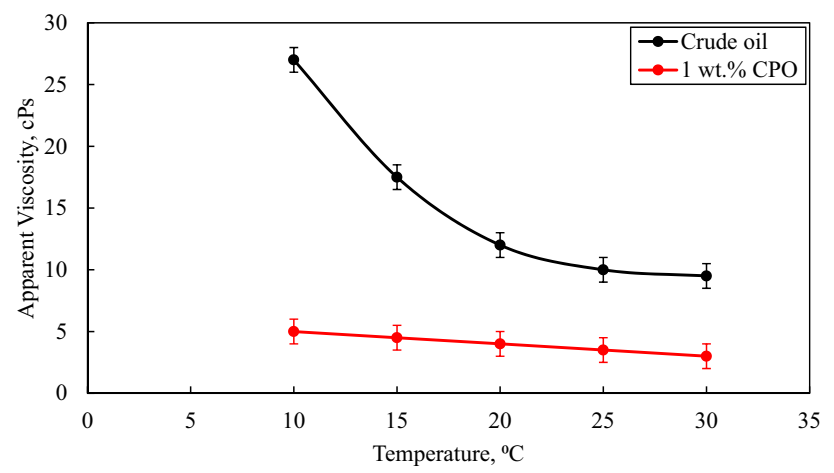

Fig. 7 Apparent viscosity of the best performing inhibitor formulation compared to the apparent viscosity of the virgin crude oil

From Figs. 6 and 7, it can be clearly seen that 1 wt.\% $\mathrm{CPO}$ is the most efficient viscosity reducer among the inhibitors tested followed by $0.1 \mathrm{wt} . \%$ EVA, $1 \mathrm{wt} . \% \mathrm{CPKO}$ and finally $1 \mathrm{wt} . \%$ TEA. The high efficiency of $1 \mathrm{wt} . \%$ CPO can be attributed to the high composition of oleic acid present. This result shows that an increase in the concentration until the critical concentration of the additives causes the nonpolar section of the additive to co-crystallize with the paraffin wax, while the polar part hinders the crystal growth causing the decrease in viscosity. However, at concentrations above $1 \mathrm{wt} . \%$, the efficiency of CPO decreases due to the fact that the nonpolar part acts as potential sites for the wax crystals to agglomerate. In addition to the apparent viscosity, the plastic viscosity of the virgin crude oil as well as in the presence of inhibitors in various concentrations were calculated and analyzed.

\section{Plastic viscosity}

Plastic viscosity is defined as the resistance of the fluid to flow (Patel et al. 2017). To obtain a better understanding of the effect of the inhibitors tested under the desired concentrations on the plastic viscosity of the crude oil, Figs. 8, 9, 10 and 11 illustrate the plastic viscosity against temperature. All the inhibitors tested below the concentration of $1 \mathrm{wt} . \%$ have a relatively lower plastic viscosity value as compared to virgin crude oil.

From Fig. 8, it can be seen that at low temperatures close to the pour point of the crude oil, all concentrations of CPO tested were able to reduce the plastic viscosity of the crude oil as all the viscosity curves at temperatures below $20{ }^{\circ} \mathrm{C}$ are below the viscosity curve of virgin crude oil. Furthermore, a similar trend to the apparent viscosity can be seen as the concentration of the CPO additive increases from $0.1 \mathrm{wt} . \%$ to $1 \mathrm{wt} . \%$, where the plastic viscosity decreases with $1 \mathrm{wt} . \%$ concentration being the lowest plastic viscosity. However, as the concentration of the CPO inhibitor further increases to $5 \mathrm{wt} . \%$ and $10 \mathrm{wt} . \%$, the plastic viscosity

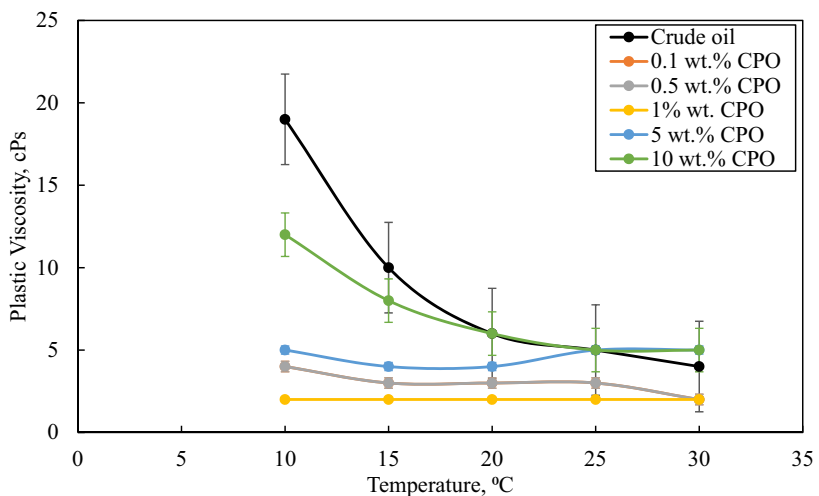

Fig. 8 Plastic viscosity of crude oil in the presence of various concentrations of $\mathrm{CPO}$

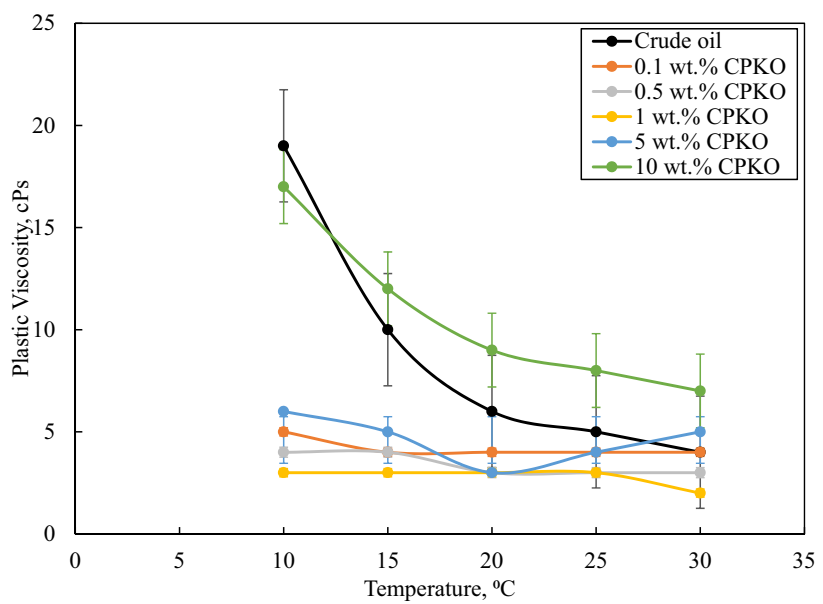

Fig. 9 Plastic viscosity of crude oil in the presence of various concentrations of CPKO

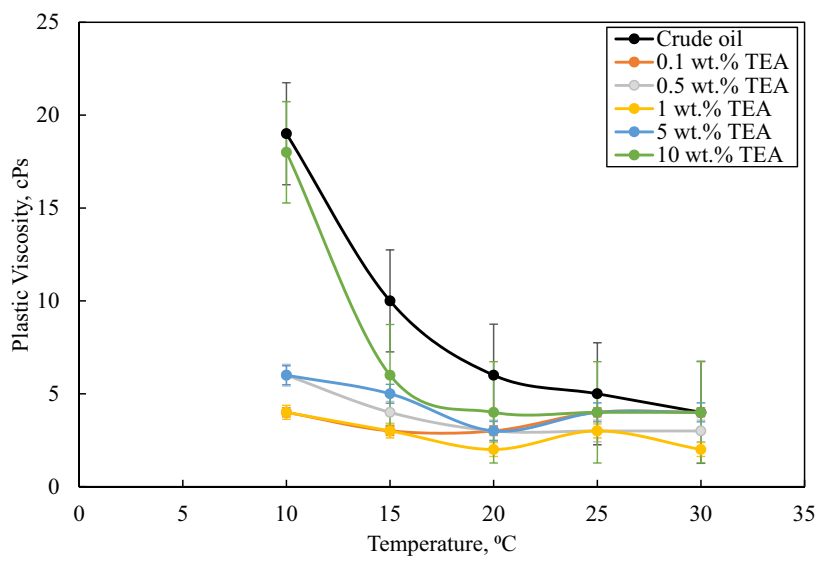

Fig. 10 Plastic viscosity of crude oil in the presence of various concentrations of TEA 


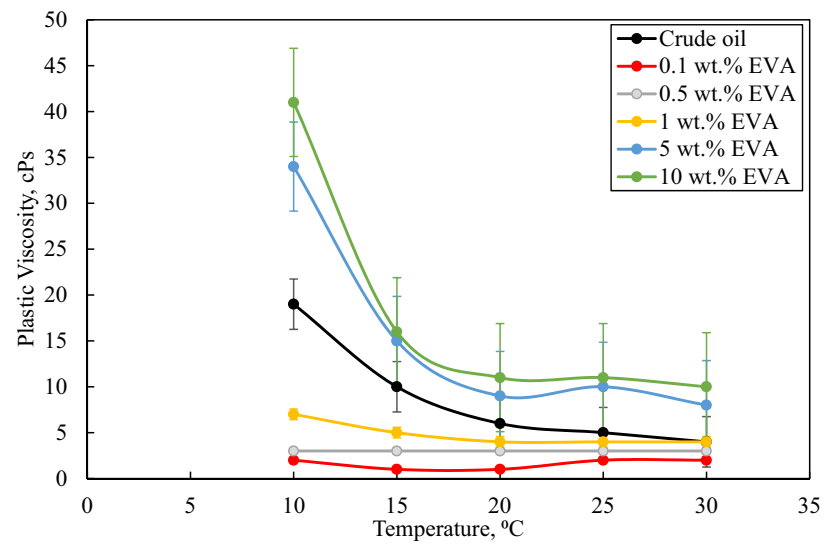

Fig. 11 Plastic viscosity of crude oil in the presence of various concentrations of EVA

increases with $10 \mathrm{wt} . \%$ CPO portraying the highest plastic viscosity among the $\mathrm{CPO}$ concentration tested. Therefore, the critical concentration in terms of plastic viscosity of $\mathrm{CPO}$ is also $1 \mathrm{wt} . \%$ for Chenor crude oil. In addition, the plastic viscosity of $5 \mathrm{wt} . \% \mathrm{CPO}$ and $10 \mathrm{wt} . \% \mathrm{CPO}$ at temperatures of $25^{\circ} \mathrm{C}$ and $30^{\circ} \mathrm{C}$ can be seen to be similar to the plastic viscosity of virgin crude oil.

From Fig. 9, it is portrayed that at low temperatures near the pour point of the crude oil, all concentrations of CPKO tested were able to reduce the plastic viscosity of the crude oil as all the viscosity curves at temperatures at $10{ }^{\circ} \mathrm{C}$ are below the viscosity curve of virgin crude oil. However, as the temperature increases, the plastic viscosity of $10 \mathrm{wt}$ \% CPKO is seen to be higher than the plastic viscosity of virgin crude oil. Furthermore, a similar trend to the apparent viscosity can be seen as the concentration of the CPKO additive increases from $0.1 \mathrm{wt} . \%$ to $1 \mathrm{wt} . \%$, where the plastic viscosity decreases with $1 \mathrm{wt} . \%$ concentration being the lowest plastic viscosity. However, as the concentration of the CPKO inhibitor further increases to $5 \mathrm{wt} . \%$ and $10 \mathrm{wt} . \%$, the plastic viscosity increases with $10 \mathrm{wt}$ \% CPKO portraying the highest plastic viscosity among the $\mathrm{CPKO}$ concentration tested. The plastic viscosity trend observed of $5 \mathrm{wt} . \% \mathrm{CPKO}$ at $20{ }^{\circ} \mathrm{C}$ can be attributed to the accuracy and the sensitivity of the Fann viscometer used. However, the plastic viscosity at temperatures close to the pour-point temperature of the crude oil shows that the plastic viscosity of the crude oil in the presence of $5 \mathrm{wt} . \%$ CPKO increases as compared to the plastic viscosity in the presence of $1 \mathrm{wt} . \%$ CPKO. Therefore, the critical concentration in terms of plastic viscosity of CPKO is also $1 \mathrm{wt} . \%$ for Chenor crude oil. In addition, the plastic viscosity of $5 \mathrm{wt} . \%$ CPKO at the temperatures of $30^{\circ} \mathrm{C}$ can be seen to be similar to the plastic viscosity of virgin crude oil, while $10 \mathrm{wt} . \%$ CPKO is significantly higher than the virgin crude oil.

Based on Fig. 10, all the concentrations of the TEA inhibitor tested were able to reduce the plastic viscosity of the crude oil as all the viscosity curves at temperatures are below the viscosity curve of virgin crude oil. Furthermore, a similar trend to the apparent viscosity can be seen as the concentration of the TEA additive increases from $0.1 \mathrm{wt} . \%$ to $1 \mathrm{wt} . \%$, where the plastic viscosity decreases with $1 \mathrm{wt} . \%$ concentration being the lowest plastic viscosity. However, as the concentration of the TEA inhibitor further increases to $5 \mathrm{wt} . \%$ and $10 \mathrm{wt} . \%$, the plastic viscosity increases with $10 \mathrm{wt} . \%$ TEA portraying the highest plastic viscosity among the TEA concentration tested but is still lower than that of the virgin crude oil. The fluctuating plastic viscosity trend observed of $5 \mathrm{wt}$ \% CPKO and $1 \mathrm{wt}$ \% CPKO can be attributed to the accuracy and the sensitivity of the Fann viscometer used. However, as highlighted earlier, the plastic viscosity of the crude oil in the presence of the additives close to the pour-point temperature shows that $1 \mathrm{wt} . \%$ TEA is the optimum concentration and the further increase of the additive concentration deteriorates the efficiency of the additive as a flow improver. Therefore, the critical concentration in terms of plastic viscosity of TEA is also $1 \mathrm{wt}$.\% for Chenor crude oil. In addition, the plastic viscosity of $0.1 \mathrm{wt} . \%$, $5 \mathrm{wt} . \%$ and $10 \mathrm{wt} . \%$ TEA at the temperatures of $30^{\circ} \mathrm{C}$ can be seen to be similar to the plastic viscosity of virgin crude oil.

As portrayed in Fig. 11, EVA inhibitor was able to reduce the plastic viscosity of the crude oil at concentrations below $1 \mathrm{wt} . \%$ with the most efficient concentration being $0.1 \mathrm{wt} . \%$ EVA. As the concentration further increases, the plastic viscosity can be seen to increase indicating that the critical concentration of EVA inhibitor to be $0.1 \mathrm{wt}$.\% EVA. Furthermore, it can also be seen that at $5 \mathrm{wt} . \%$ and $10 \mathrm{wt} . \%$ EVA concentration, the plastic viscosity is even higher than that of the virgin crude oil. The reason to this will be discussed in further details later in this section. In addition, the concentration which has the lowest plastic viscosity of each inhibitor is plotted as illustrated in Fig. 12. Furthermore, the plastic viscosity of the best performing inhibitors compared to the plastic viscosity of the virgin crude oil is as shown in Fig. 13.

From Figs. 12 and 13, 0.1 wt.\% EVA is the most efficient plastic viscosity reducer among the inhibitors tested followed by $1 \mathrm{wt} . \%$ CPO, $1 \mathrm{wt} . \%$ CPKO and finally $1 \mathrm{wt} . \%$ TEA. It should be noted that, at low temperatures near the pour point of the Chenor crude oil $\left(10^{\circ} \mathrm{C}\right), 1 \mathrm{wt} . \% \mathrm{CPKO}$ is much more efficient at reducing the plastic viscosity of the crude oil than $1 \mathrm{wt} . \%$ TEA. In addition to the apparent viscosity, the yield value of the virgin crude oil as well as in the presence of inhibitors in various concentrations were calculated and analyzed.

\section{Yield value}

Yield value is defined as the resistance or stress required of a fluid to start flowing (Patel et al. 2017). The yield value 


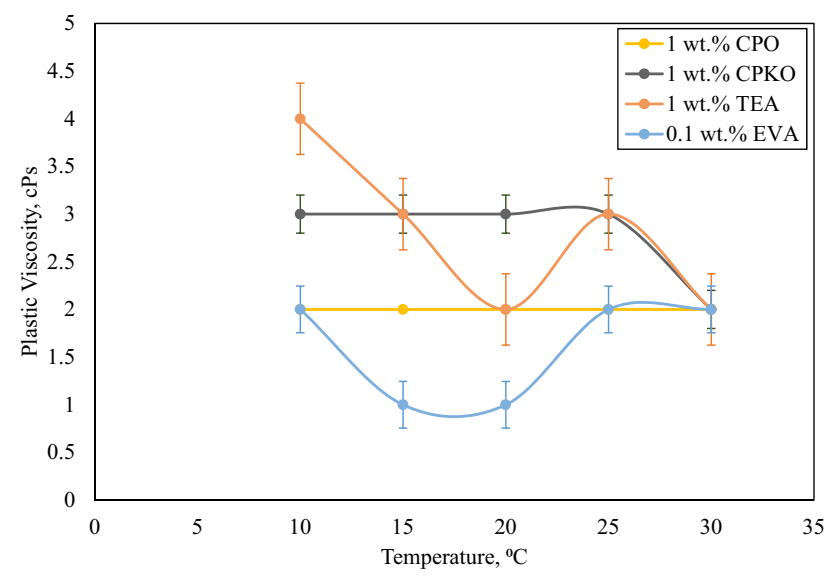

Fig. 12 Plastic viscosity of the most efficient inhibitor concentrations

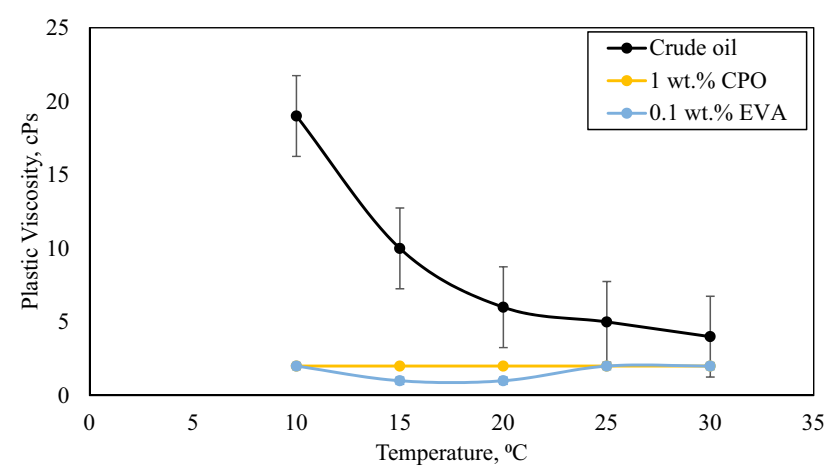

Fig. 13 Plastic viscosity of the best performing inhibitors compared to the plastic viscosity of the virgin crude oil

obtained shows that the increase in inhibitor concentration until the critical concentration portrays a vital decrease in yield value when compared to the virgin crude oil. Figs. 12, 13, 14 and 15 illustrates the yield value of the crude oil as well as the yield value in the presence of inhibitors under the different temperatures tested.

From Fig. 14, it can be seen that all concentrations of CPO tested were able to reduce the yield value of the crude oil as all the yield value curves are below the yield value curve of virgin crude oil. As the concentration of the CPO increases from $0.1 \mathrm{wt} . \%$ to $1 \mathrm{wt} . \%$ concentration, the yield value decreases but as the concentration further increases to $5 \mathrm{wt} . \%$ and $10 \mathrm{wt} . \%$, the yield value begins to increase, indicating that the critical concentration of CPO in terms of yield value is also $1 \mathrm{wt} . \%$.

From Fig. 15, as the inhibitor concentration of CPKO increases from $0.1 \mathrm{wt} . \%$ to $1 \mathrm{wt} . \%$, the yield value decreases but then increases to $5 \mathrm{wt} . \%$ and then decreases at $10 \mathrm{wt} . \%$. Furthermore, at low temperature of $10{ }^{\circ} \mathrm{C}, 0.1 \mathrm{wt} . \%$ CPKO has a higher yield value then virgin crude oil. In addition, at high temperatures, $5 \mathrm{wt}$ \% CPKO has the lowest yield

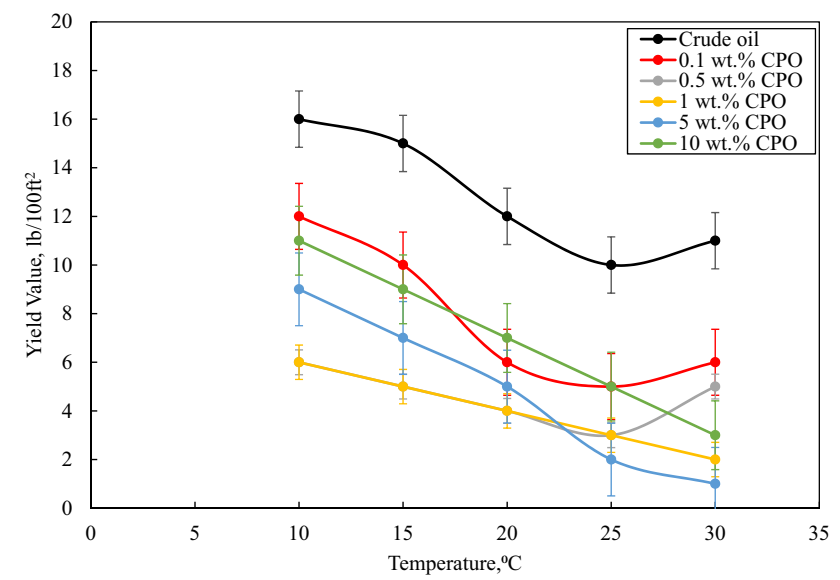

Fig. 14 Yield value of crude oil in the presence of various concentrations of $\mathrm{CPO}$

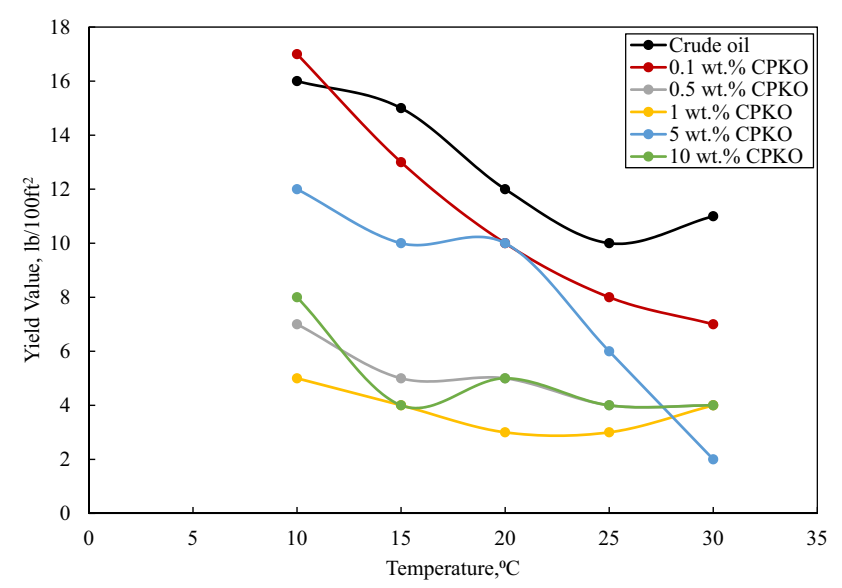

Fig. 15 Yield value of crude oil in the presence of various concentrations of CPKO

value at $2 \mathrm{lb} / 100 \mathrm{ft}^{2}$. As the concentration of the CPKO increases from $0.1 \mathrm{wt} . \%$ to $1 \mathrm{wt} . \%$ concentration, the yield value decreases but as the concentration further increases to 5 and $10 \mathrm{wt} . \%$, the yield value begins to increase, indicating that the critical concentration of CPKO in terms of yield value is also $1 \mathrm{wt} . \%$.

From Fig. 16, as the inhibitor concentration of TEA increases from $0.1 \mathrm{wt} . \%$ to $1 \mathrm{wt} . \%$, the yield value decreases but then increases at $5 \mathrm{wt} . \%$ and $10 \mathrm{wt} . \%$ concentrations, indicating that the critical concentration of TEA is also $1 \mathrm{wt} . \%$. Furthermore, at low concentration of $0.1 \mathrm{wt} . \%$ TEA, the yield value is higher than the virgin crude oil from temperature $10{ }^{\circ} \mathrm{C}$ to $25^{\circ} \mathrm{C}$ but then decreases at $30{ }^{\circ} \mathrm{C}$. In addition, at high concentration of $10 \mathrm{wt} . \%$ TEA, the yield value obtained is also higher than the yield value of the virgin crude oil, but at high temperature of $30{ }^{\circ} \mathrm{C}$, the yield value is similar to the yield value of virgin crude oil at $11 \mathrm{lb} / 100 \mathrm{ft}^{2}$. 


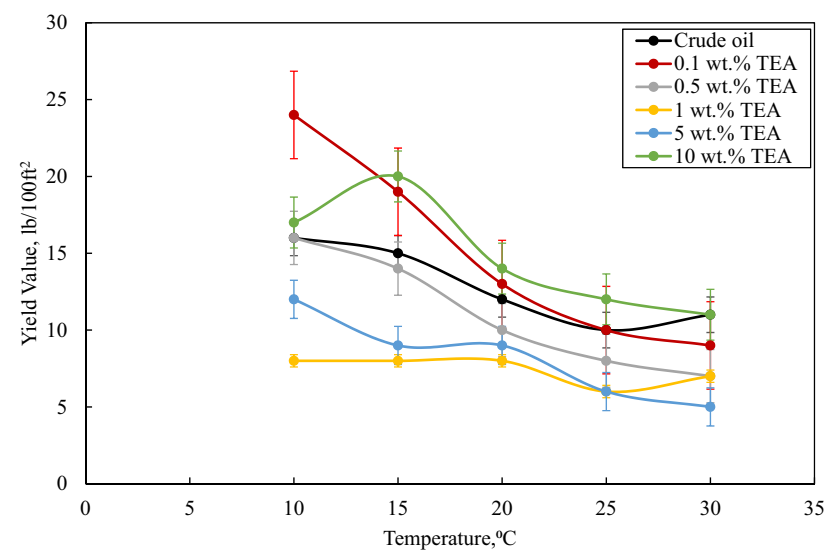

Fig. 16 Yield value of crude oil in the presence of various concentrations of TEA

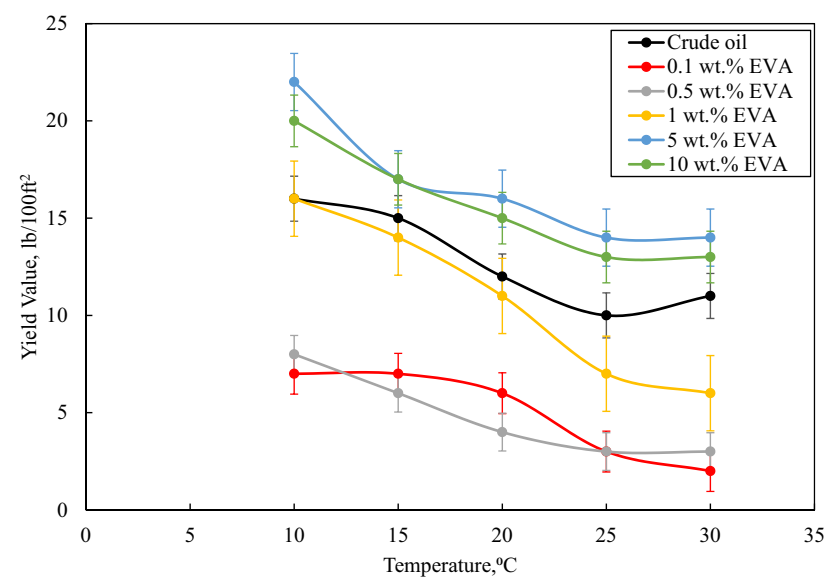

Fig. 17 Yield value of crude oil in the presence of various concentrations of EVA

Based on Fig. 17, the lowest yield value was obtained in the presence of $0.1 \mathrm{wt} . \%$ and $0.5 \mathrm{wt} . \% \mathrm{EVA}$, while as the concentration increases, the yield value increases. In addition, at $5 \mathrm{wt} . \%$ and $10 \mathrm{wt} . \%$ EVA, the yield value can be seen to be higher than the yield value of virgin crude oil. The critical concentration in terms of yield value for the case of EVA can be concluded as $0.5 \mathrm{wt} . \%$. However, at the pour-point temperature, $0.1 \mathrm{wt}$ \% EVA performs better. To get a better understanding of the effect of the inhibitor on the yield value of the crude oil, the concentration which has the lowest yield value of each inhibitor is plotted as illustrated in Fig. 18. The inhibitor with the lowest yield value as compared to the virgin Chenor crude oil is as shown in Fig. 19.

From Figs. 18 and 19, 1 wt.\% CPKO is the most efficient yield value reducer among the inhibitors tested followed by $1 \mathrm{wt} . \%$ CPO, $10 \mathrm{wt} . \%$ EVA and finally $1 \mathrm{wt} . \%$ TEA. It should be noted that, at high temperatures at $30{ }^{\circ} \mathrm{C}, 1 \mathrm{wt} . \%$ $\mathrm{CPO}$ is much more efficient at reducing the yield value of

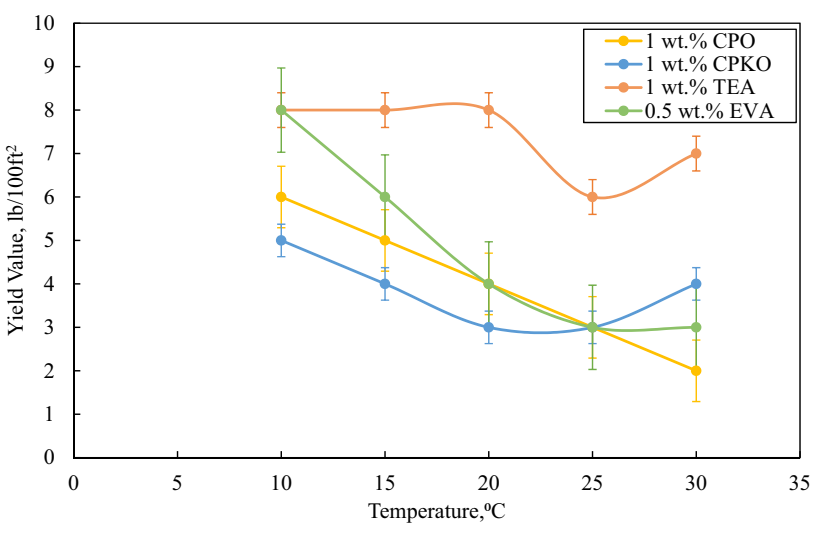

Fig. 18 Yield value of the most efficient inhibitor concentrations

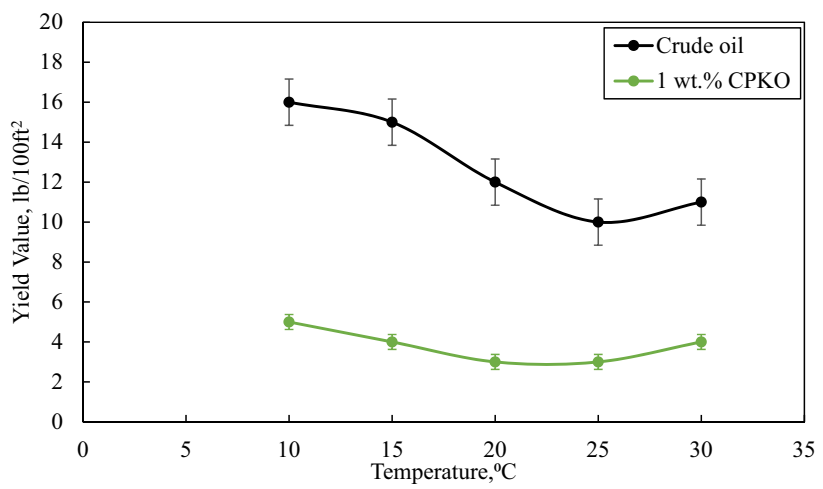

Fig. 19 The yield value of the best performing inhibitors compared to the yield value of the virgin crude oil

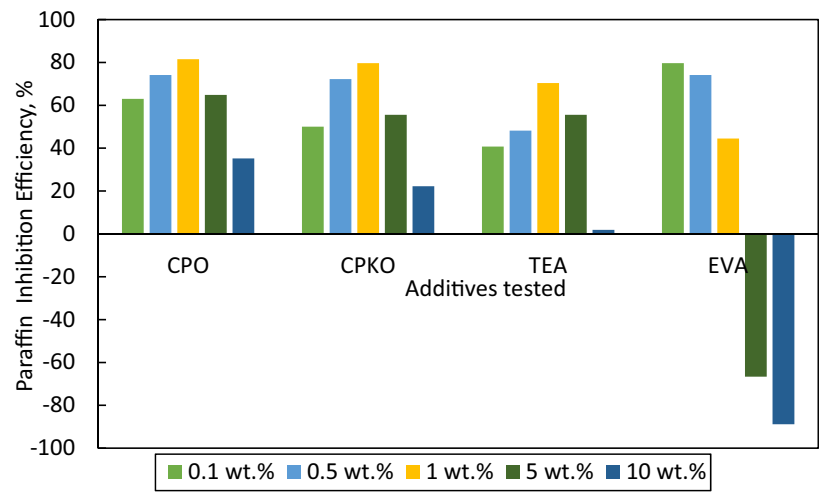

Fig. 20 PIE in terms of apparent viscosity at $10^{\circ} \mathrm{C}$

the crude oil than 1 wt.\% CPKO. Figures 20, 21 and 22 portrays the PIE of apparent viscosity, plastic viscosity and yield value in the presence of each inhibitor at pour-point temperature $\left(10^{\circ} \mathrm{C}\right)$, respectively.

From Figs. 20 and 21, it can be seen that in terms of apparent viscosity, as the concentration of $\mathrm{CPO}, \mathrm{CPKO}$ 


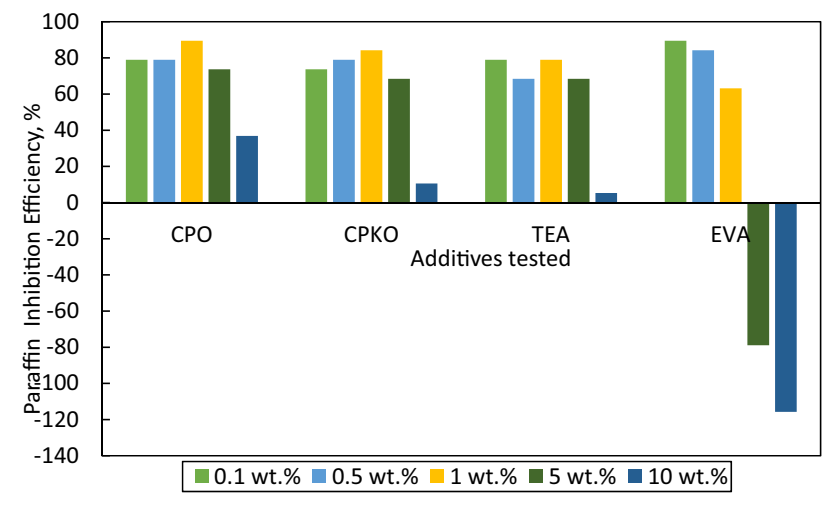

Fig. 21 PIE in terms of plastic viscosity at $10{ }^{\circ} \mathrm{C}$

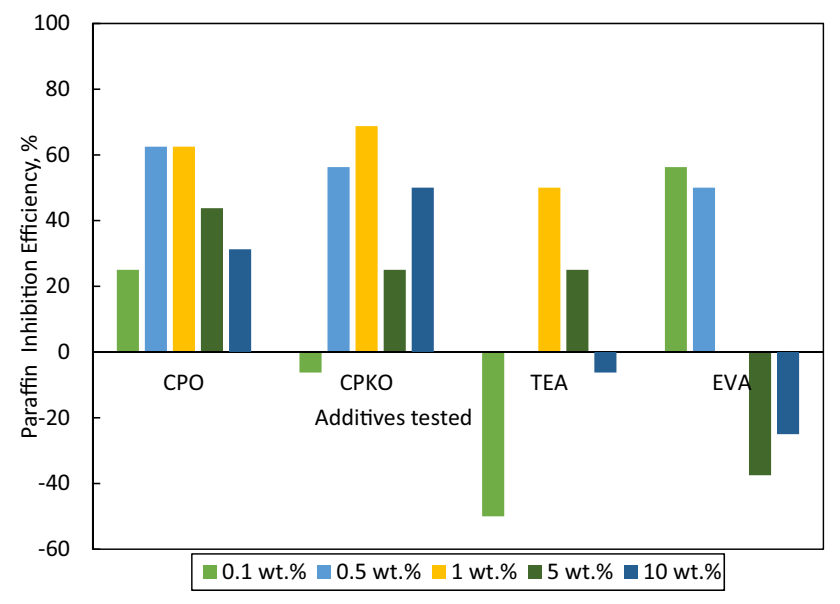

Fig. 22 PIE in terms of yield value at $10{ }^{\circ} \mathrm{C}$

and TEA increases, the PIE increases until $1 \mathrm{wt} . \%$ and then declines, while the PIE of EVA decreases as the concentration increases pass $0.1 \mathrm{wt} \%$. The negative PIE of $5 \mathrm{wt} . \%$ and $10 \mathrm{wt} . \%$ EVA indicates an increase in the apparent and plastic viscosity. Furthermore, the highest PIE in terms of apparent viscosity is $1 \mathrm{wt}$. $\mathrm{CPO}$ at $81.48 \%$, while in terms of plastic viscosity, the highest PIE is 1 wt.\% CPO and $0.1 \mathrm{wt} . \%$ EVA at $89.47 \%$.

Meanwhile, the PIE in terms of yield value at the pourpoint temperature as portrayed in Fig. 22 shows a similar pattern as the apparent viscosity and plastic viscosity where when the concentration increases, the PIE of CPO, CPKO and TEA increases until $1 \mathrm{wt} . \%$, then decreases while the PIE of EVA decreases as the concentration increases above $0.1 \mathrm{wt} . \%$. However, the PIE of $0.1 \mathrm{wt} . \%$ CPKO, $0.1 \mathrm{wt} . \%$ TEA, 10 wt. $\%$ TEA, 5 wt. $\%$ EVA and 10 wt. $\%$ EVA is negative indicating an increase in yield value. Moreover, the highest PIE in terms of yield value is $1 \mathrm{wt} \% \mathrm{CPKO}$ at $68.75 \%$.

From the apparent viscosity, plastic viscosity and yield value results, it was observed that the use of inhibitors decreases the viscosity values as well as the yield value considerably up to a critical concentration which varies according to the inhibitors used. In all the inhibitors tested, it can be seen that there is a critical concentration where each inhibitor performs the best. Above the critical concentration, the further addition of inhibitors increases the site for wax crystals to agglomerate and thus increases the viscosity of the crude oil.

In terms of CPO and CPKO, the efficiency of the inhibitors used is determined by the composition of oleic acid present where the CPO which has the higher composition of the fatty acid portrays a better efficiency in reducing the viscosity of the crude oil. This result shows that an increase in the concentration until the critical concentration of the inhibitors causes the nonpolar section of the inhibitor to cocrystallize with the paraffin wax while the polar part hinders the crystal growth causing the decrease in viscosity. However, at concentrations above $1 \mathrm{wt} . \%$, the efficiency of the inhibitor decreases in both palm oil-based inhibitors. This may be due to the fact that the nonpolar part acts as potential sites for the wax crystals to agglomerate.

Besides, other esters of oleic acids such as stearic acid and linoleic acid may form strong $\mathrm{H}$-bonds with resin where the mutual overlapping aromatic ring planes of oleate-resin is greatly reduced which in turns reduces the crude oil's viscosity significantly (Akinyemi et al. 2018; Soni et al. 2005; Taiwo et al. 2012). Based on Table 1, CPO contains the highest percentage of oleic acid followed by CPKO. However, CPKO contains a higher percentage of lauric acid. The high content of oleic acid in CPO and lauric acid in CPKO contains hydroxyl polar group which may have played essential roles in their efficiency as flow improvers by reducing the viscosity of Chenor crude oil.

In addition, TEA also portrayed significant potential as flow improver in the Chenor crude oil at similar concentrations as the palm-based inhibitors. The effectiveness of TEA as a flow improver is due to the dissolution of the paraffin wax. This may be due to the hydroxyl groups present in TEA where in low concentration, it prevents the agglomeration of wax crystals but when added in high quantity, the hydroxyl group becomes potential site for agglomeration. Therefore, causing the viscosity of the crude oil to increase. This performance of TEA on Chenor crude oil was also observed but other researchers (Hafiz and Khidr 2007; Popoola et al. 2015; Soni et al. 2005).

Moreover, polymeric additives such as EVA inhibit wax deposition by altering the structure and growth of wax crystals. Hence, EVA alters the morphology of the crude oil by producing lots of crystallization sites or nucleus which prevents the growth of crystals. The reduction of crystal growth causes the inability of the wax crystals to form wax crystals networks reducing the deposited crystal strength (Anisuzzaman et al. 2017; Gilby 1983; Zhang et al. 2008). However, as the concentration of EVA increases, the PIE of

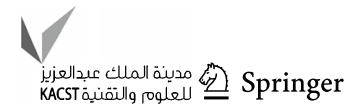


EVA decreased drastically especially above $1 \mathrm{wt} . \%$ concentration. This is due to the possibility that the EVA additives are behaving as supplementary suspended particles in the crude oil which deteriorates the efficiency of the polymer to inhibit wax deposition. This confirms that the increase in wax deposits is influenced by the concentration of wax inhibitor utilized and as the concentration reaches the optimum value, it alters the wax crystallization behavior by implementing more structures to disturb and reconcile with edge of the developing wax crystals.

\section{Conclusion}

As a conclusion, the results obtained from the rheological test prove that palm oil can be used to form a barrier to prevent the formation of wax crystal networks and hence hinder wax deposition as efficient as the commercial wax inhibitors. This was evidently seen where the addition of $1 \mathrm{wt} . \%$ of CPO into the crude oil at $10{ }^{\circ} \mathrm{C}$, where the viscosity reduction was at the highest, which was better than any concentration of the commercial inhibitors tested. In addition, TEA and EVA being a potentially hazardous chemical inhibitor further justifies the use of $\mathrm{CPO}$ and $\mathrm{CPKO}$ as a wax inhibitor in which the optimum concentration to use CPO was $1 \mathrm{wt} . \%$ and the optimum concentration to use CPKO was $0.5 \mathrm{wt}$.\% However, further investigation should be conducted on the effect of CPO and CPKO on the wax content analysis as well as the reduction of deposited wax using a cold finger or cold flow apparatus. Besides, future researchers can also investigate the effect of adding $\mathrm{CPO}$ and $\mathrm{CPKO}$ on the pour point reduction of the crude oil.

Authors' contributions All authors contributed to the study conception and design. Material preparation, data collection and analysis were performed by TR, JZ, Dr CW and Dr HH. The first draft of the manuscript was written by TR, and all authors commented on previous versions of the manuscript. All authors read and approved the final manuscript.

Funding Research grant from University Technology Petronas.

Data availability Available

\section{Declarations}

Conflicts of interest The author declare that there is no conflict of interest.

Open Access This article is licensed under a Creative Commons Attribution 4.0 International License, which permits use, sharing, adaptation, distribution and reproduction in any medium or format, as long as you give appropriate credit to the original author(s) and the source, provide a link to the Creative Commons licence, and indicate if changes were made. The images or other third party material in this article are included in the article's Creative Commons licence, unless indicated otherwise in a credit line to the material. If material is not included in the article's Creative Commons licence and your intended use is not permitted by statutory regulation or exceeds the permitted use, you will need to obtain permission directly from the copyright holder. To view a copy of this licence, visit http://creativecommons.org/licenses/by/4.0/.

\section{References}

Akinyemi OP, Udonne JD, Efeovbokhan VE, Ayoola AA (2016) A study on the use of plant seed oils, triethanolamine and xylene as flow improvers of Nigerian waxy crude oil. J Appl Res Technol 14(3):195-205. https://doi.org/10.1016/j.jart.2016.04.006

Akinyemi OP, Udonne JD, Oyedeko KF (2018) Study of effects of blend of plant seed oils on wax deposition tendencies of Nigerian waxy crude oil. J Petrol Sci Eng 161:551-558. https://doi.org/10.1016/j. petrol.2017.12.017

Al-Jawad M, Hassan O (2012) Comprehensive model for flash calculations of heavy oils using the soave-redlich-kwong equation of state. North Africa Technical Conference and Exhbition. Society of Petroleum Engineers

Anisuzzaman SM, Abang S, Bono A, Krishnaiah D, Karali R, Safuan MK (2017) Wax inhibitor based on ethylene vinyl acetate with methyl methacrylate and diethanolamine for crude oil pipeline. IOP Conf Ser Mater Sci Eng. https://doi.org/10.1088/1757-899x/206/1/012074

Azzam EMS, Ahmed SA, Abd El-Salam HM, Abd Allha OA, Gad EAM (2018) Synthesis and characterization of $\mathrm{N}$-alkyl-2-aminopyridinum oligomers as pour point depressants for crude oil. Egypt J Petrol 27(4):1337-1344. https://doi.org/10.1016/j.ejpe.2018.09.001

Brown L (2002) Flow assurance: A? Discipline. Offshore Technology Conference

Garcia M (2000) Crude oil wax crystallization. The effect of heavy n-paraffins and flocculated asphaltenes. Energy Fuels 14(5):1043-1048

Gilby GW (1983) The use of ethylene-vinyl acetate copolymers as flow improvers in waxy crude oil. Paper presented at the Royal Society of Chemistry, London

Hafiz AA, Khidr TT (2007) Hexa-triethanolamine oleate esters as pour point depressant for waxy crude oils. J Petrol Sci Eng 56(4):296302. https://doi.org/10.1016/j.petrol.2006.10.003

Kelechukwu EM, Said Al-Salim H, Saadi A (2013) Prediction of wax deposition problems of hydrocarbon production system. J Petrol Sci Eng 108:128-136. https://doi.org/10.1016/j.petrol.2012.11.008

Malaysian Palm Oil Council (2012) Oil palm plantation. Retrieved from http://www.mpoc.org.my/Malaysian_Palm_Oil_Industry.aspx

McCain Jr W (2017) Properties of petroleum fluids. PennWell Corporation

Ottha D, Al-Jawad M (2006) Well performance analysis based on flow calculations and IPR. J Eng 12(3):822-841

Patel MR, Chitte PS, Bharambe DP (2017) Oleic acid based polymeric flow improvers for Langhnaj (North Gujarat, India) crude oil. Egypt J Petrol 26(4):895-903. https://doi.org/10.1016/j.ejpe.2015.04.006

Popoola CA, Ayo JA, Adedeji OE, Akinleye O (2015) Triethanolamine (TEA) as flow improver for heavy crude oils. IOSR J Appl Chem 8(3):34-38

Ridzuan N, Adam F, Yaacob Z (2014) Molecular recognition of wax inhibitor through pour point depressant. Spe(November), 1-9. https://doi.org/10.2523/17883-MS

Sadeq D, Al-Fatlawi O, Iglauer S, Lebedev M, Smith C, Barifcani A (2020) Hydrate equilibrium model for gas mixtures containing methane, nitrogen and carbon dioxide. Offshore Technology Conference

Soni HP, Bharambe DP, Nagar A, Kiranbala. (2005) Synthesis of chemical additives and their effect on Akholjuni crude oil. Indian J Chem Technol 12:55-61

Soni HP, Agrawal KS, Nagar A, Bharambe DP (2010) Designing maleic anhydride- $\alpha$-olifin copolymeric combs as wax crystal growth nucleators. Fuel Process Technol 91(9):997-1004 
Sulaimon AA, Yusoff MH (2014) Wax and asphaltene deposition tendency of Malaysian crude oils. International Conference on Integrated Petroleum Engineering and Geosciences, Kuala Lumpur

Taiwo E, Otolorin J, Aafolabi T (2012) Crude oil transportation: Nigeria Niger-delta waxy crude. In: Crude oil exploration in the world. InTech, Rijeka, pp 135-154

Zhang J, Zhang M, Wan J, Li W (2008) Theoretical study of the prohibited mechanism for ethylene/vinyl acetate co-polymers to the wax crystal growth. J Phys Chem B 112(1):36-43. https://doi.org/10. 1021/jp073052k

Publisher's Note Springer Nature remains neutral with regard to jurisdictional claims in published maps and institutional affiliations. 